\title{
Reflexiones sobre algunos de los personajes de Tiempo de Silencio
}

Robin W. Fiddian

Oxford, Gran Bretaña

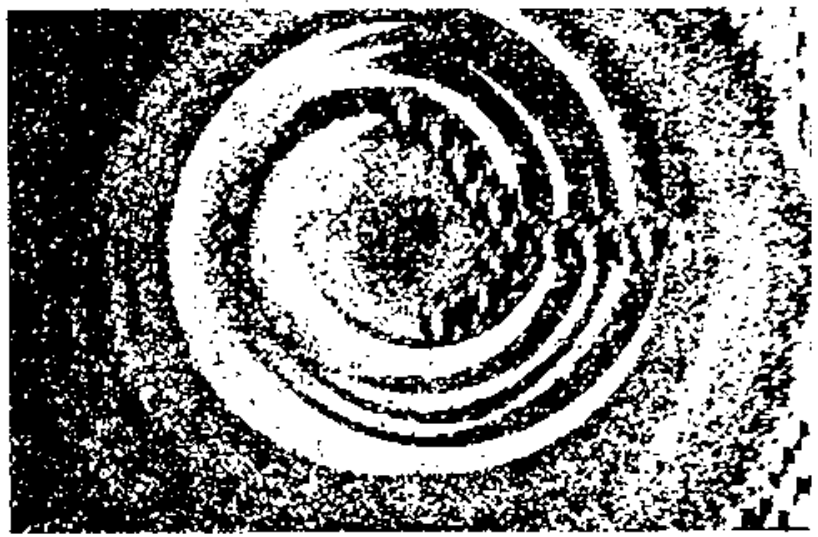



Hoy, a un cuarto de siglo desde la publicación de la primera edición de Tienpo de silencio, la opinión crítica da por scntada la singular importancia de este título cn la historia de la novelística española, a la vez que reconoce su inmensa complujidad como obra literaria. De hecho, no deja de llamar la atención cl alto grado de elaboración artística en la novela de Luis Martín Santos, que es el resultado de la fusión de un gran número de elementos de contenido, como son los temas sociales, históricos, míticos, sicoanalílicos, ideológicos y filosólicos, con otros tantos valores formalcs entre los que habría que destacar ora el lenguaje, ora la estructura narrativa, ora los personajes.

En esta ocasión el aspecto de Tiempo de silencio que nos interesa es precisamente el de los personajes, algunos de los cuales nos proponemos examinar en las páginas que siguen, inquiriendo sobre el valor funcional que tengan dentro de un entramado de relaciones contextuales, y considerando la carga semántica que posean, en conjunto y por separado. Al cmprender nuestro análisis, partimos de la base de que las técnicas de caracterización utilizadas por Luis Martín Santos proveen una de las mejores claves para comprender su novela, ya que por un lado constituyen un vehículo de expresión de la visión personalísima que cl autor tuvo de la vida española en sus verticntes históricas, sicológicas e ideológicas, y por olro dejan entrever los variados mecanismos de representación que son inherentes a su obra, entre ellos el recurso a la alegoría, la parodia, la caricalura, y la presentación de los tipos humanos por medio de una scric de imágenes arquetípicas.

En csle último respecto conviene recordar cl episodio de la visita de Pedro, Dorita y la madre de ésta al cabaré donde se adentran en un ambiente propicio al "cnsueño, la alucinación mescalínica, cl inconsciente colectivo". Haciéndose ceo de las teorías de Carl Gustav Jung, Luis Martín Santos señala el papel que en nuestra vida ś́quica desempeñan los arquetipos, o imágenes "de lo que deseamos desde la cama solitaria de los trece años de edad" (219), y demuestra cómo en el cscenario del cabaré esos sueños y descos toman forma en la persona de la "supervedette máxima" quien aparece ante el público "cubierta toda ella de papel de plata o cscamas de pez" $(221)^{\mathrm{l}}$. Esta cantante-sirena, que es "la imagen policromada de la mujer" (222), reúne cualidades de to prohibido y lo ansiado que están puestas al servicio del poder del

(1) Las citas cen cl texto de este artíeulo están sacadas de la novena edición de Tientpo de silencio, pulılicada cn Barcelona en 1971 . 
Estado, ya que, al seducir y embelesar a los espectadores, hace que "olviden sus enajenaciones" mediante la participación en "una euforia incesante que a la mala alimentación sustihuyera" (220).

El cpisodio nos muestra al autor utilizando unas imágenes arquetípicas (las de la sirena, la hurí y la vedette) para poner al descubierto la función ideológica de las formas tradicionales de representar a la mujer $\mathrm{en}$ cl curso de la historia y la cultura occidentales. Pedro da un ejemplo de esta tendencia al considerar "la teoría alegórica en que la lujuria es una mujer desnuda con una manzana en la mano y la soberbia una mujer vestida con una corona en la cabeza" (139); Matías hace hincapié en la misma tendencia al imaginar la seducción de Pedro, por parte de Dorita, como un aclo de emasculación que realiza una devoradora de hombres amenazante y traidora (162). Está claro que tales tópicos e imágenes resumen actitudes sexistas y misóginas que son marcadamente censurables, pero eso no obsta para que cl autor aproveche un amplio repertorio de los mismos, supeditándolos a un proyecto crítico de gran envergadura. Citemos cl caso de la abuela de Dorita cuyo carácter tiene su origen en la tradición literaria española: esta mujer sin nombre es una Celestina chapada a la antigua que representa "Ia fcmineidad vuelta astucia"(97); se asemcja tambićn a otros personajes literarios, incluida la Bernarda Alba de García Lorca, en cuanto hace el papel de matriarca autoritaria quien "a pesar de su edad era ordeno y mando"(36).

Mitad estereotipo, mitad caricatura, la abucla de Dorita juzga a los hombres con arreglo a unas ideas simplistas que contraponen al tipo del guerrero-conquistador con los jóvenes inocentes cuyo patrono es San Luis Gonzaga'. En Tiempo de silencio es el abuelo de Dorita quien corresponde ai tipo marcial, y Pedro el que cncaja dentro del molde de San Luis Gonzaga al dar pruebas de su calidad de hombre pacífico que no sabe tratar a las mujeres. Otras imágenes estcrcotipadas del hombre incluyen la del cazador primitivo, ejemplificado aquí por Cartucho en la cscena de la verbena donde hace gala de su "gran poder viril de macho" (230), y la del torero, cuyas características más convencionales de dignidad, heroismo y popularidad se habían plasmado anteriormente en los protagonistas de Sangre y arena, de Blasco Ibánez, y Llanto por Ignacio Sánchez Mejías, de García Lorca, pero que aparccen degradadas en la novela de Martín Santos en el "torero-bailarín-marica"(22) que deshonra a la madre de Dorita y la abandona por la compañ́a de unos amigos "todos de su estilo, como medio hembras también" (23). A través de este personajc paródico, Luis Martín Santos desmiente uno de los mitos esenciales de "la España de pandereta" tan burdamente idealizada por ignorantcs turistas "que se obstinan cn que [kes] sean mostrados majas y toreros" (182).

La técnica de la parodia conlleva una fuerte carga de ironía en la caracterización del Muecas a quien el autor presenta primero como un "gentleman-farmer"(56), para luego insistir en su carácter violento y bárbaro. Amador le advierte a Pedro que el Muecas "es muy burro. Es exactamente un animal. Y siemprecon la navaja encima a todas partes"(33). Huelga decir que aquí la navaja es un símbolo del "dominio fálico" del hombre que recurre a la fuerza para someter a la mujer a una rclación de

(2) James Joyce (1967: 56) scñala a San Luis Gonzaga como uno de tres patronos de la santa juventud, cn su Retrato del artista como un adolescente. 
inferioridad (127). No negamos que dicho dominio se refiera también, en un sentido lato, a la superioridad de cualquier elcmento fuerte en la sociedad sobre seres más debiles; de ahí la existencia de más de una "gran madre fálica" que controle a los hombres indecisos en el libro (151). Pero es en la familia, y concretamente en el trato que da el marido a la mujer, donde esta relación de poder alcanza su mayor grado de expresión.

En Tiempo de silencio se realiza una crítica severa de las instituciones del matrimonio y de la familia en la España franquista. "La familia muequil", que comprende al "ciudadano Muecas bicn establecido" (58), "sus dos hijas núbiles", y "la mole mansa y muda de la mujer" (54), es una familia complcta, la única descrita así en la novela. Pcro lo que más llama la atención es el hecho de que sea la contraimagen de la familia ideal. Los esposos comparten "el mismo ancho camastro con hij][as] ya crecid[as] a [las] que nada puede quedar oculto"(43); esta circunstancia da un indicio de la pobreza material y la degradación moral que impera cn "los soberbios alcázares de la miseria" que habitan(42). Según cl narrador, en tales condiciones "la alianza matrimonial" de Encarna-Ricarda, la mujer del Muecas, "carece de todo significado"(43).

En el argumento de la novela, cl Muccas leva a casa unos ratoncs cancerígenos que roba del instituto donde trabajan Pedro y Amador, para que sus hijas les den cI calor que necesitan para reproducirse, colgándoselos en bolsitas alrededor del cuello; una vez que se han desarrollado, el paterfamilias los vuelve a vender al mismo instituto que de esta forma se convicrte en una importante fuente de ingresos para la familia. La conducta del Muccas, ingeniosa y singular, por cicrto, se presta a por lo menos dos interpretaciones figurativas. Quizá nosea aventurado decir que cl hecho de introducir unos ratones "de la cepa illinoica" en una chabola madrileña hacia finales del año 1949 representa, a un nivel alegórico, la inminente licgada de la ayuda económica estadounidense autorizada por los acucrdos de 1951 y 1953; conforme con este punto de vista, el Muecas sería una caricatura del Jefe de Estado cspañol quicn no tardaría en aprobar la instalación de bases militares norteamericanas en España a cambio de una serie de préstamos e inversioncs que sabemos fueron de una impotancia capital en la recuperación cconómica del país.

A otro nivel específicamente simbólico, las maniobras del Muecas designan una contaminación del ambiente familiar, dada la circunstancia que los ratones que lleva a su casa son "de una raza de ratones cancerígenos degenerada" (29). La experiencia de la familia de Dorita cs una ilustración del mismo fenómeno. En las primeras páginas de Tiempo de silencio, se nos dice que su abuclo había regresado de la campaña de Filininas "inútil para la fecundación", gracias a una infección venćrca que le contagiara una prostituta de las islas. "La esterilidad vergonzante del vicjo corone" " (180) dio al traste con las esperanzas de su mujer que hubiera querido tener más hijos, y provec otro ejemplo de la conducta de un padre o marido que hace sufrir a su familia las consccuencias de una enfermedad. En relación con este proceso de contaminación del hogar, no puede ser casual la presencia de "dos matrimonios sin hijos" (22) cntre los inquilinos de la pensión que la abucta de Dorita monta despućs de la muerte del coroncl; la casa se definc así como un microcosmos de la csterilidad hereditaria y colcetiva.

Casi todas las familias mencionadas en Tiempo de silencio padecen los efectos de enfermedades como el cáncer, la sífilis o la cstcrilidad. El matrimonio de 
Amador es estéril: por medio de una sinécdoque, el narrador describe a su mujcr como "un vientre sin hijos, todavía concupiscente" (156). En la familia de Matías, son muchas las mujeres que han muerto de cáncer. Uno de los invitados a una fiesta en casa de la madre baraja la hipótesis de que la enfermedad de la tía Dolores (cuyo nombre ostenta un cvidente carácter simbólico) sea "Cáncer de pecho"; además, insiste en recordarles a los otros invitados que "Ya se sabe que su madre tuvo cáncer y su hermana, la monja, cáncer". La narración de esta secuencia crucial termina con unas observaciones "acerca de los derechos de las mujeres en el matrimonio cuando no se ha firmado el contrato de separación de biencs" (138), y de esta forma cstablece una conexión nada equívoca entre el cáncer y la institución del matrimonio, dando a entender que ésta acarrea consecuencias dolorosas y fatales para la mujer.

Muchos críticos han resaltado la importancia de los temas de la cnfermedad y la vivisección en la novela de Martín Santos. ${ }^{3}$ Sin embargo, ninguno parece haber notado la estrecha relación que existe allí entre las enfermedades, la situación de la mujer, y la familia: en nuestra opinión, estos elementos se combinan para proyectar una imagen alegórica de la familia de España cuyos miembros son las clases socialcs y las principales instituciones de la nación. Las víctimas más notables de las enfermedades que nos conciernen son: una monja (que representa las santas Ordenes, y, por ende, la Iglesia), mucrta de cáncer; un coronel (las Fuerzas Armadas), contagiado de sífilis en una guerra colonial; dos matrimonios estériles de "funcionarios del Ministerio de Gobernación" de Madrid (cs decir, la sede del gobicrno nacional); un policía cuya madre "murió de cáncer" (196); otro policía que sufre tránstomos intestinales con "retortijoncillos y hazmerreires hidroaćrcos" (160). "Los Institutos, los Concejos, las doctas Corporaciones [y] las venerabies Casas matrices" son también organismos enfermos (206-207); al usar el sustantivo 'matriz' con función de adjetivo en la frase 'Casas matrices', el autor subraya la vulnerabilidad de cualquicr institución, vb. gr. el centro de investigación donde Pedro hace experinentos con células cancerosas, al cáncer que va atacando cl conjus politicum del paíst.

El cuadro así pintado del estado de la nación es sumamente sombrío y desalentador. Sin embargo, hay una célula -o unidad- de la familia mayor de España que está libre de los cfectos del cáncer: nos referimos a la familia del Muccas y, principalmente, a las tres mujeres que la componen. Es curioso que Encarna y sus dos hijas gocen de inmunidad ante las enfermedades, y significativo el uso de símbolos naturales de la tierra y el agua para distinguirlas de otros personajes que son portadores de valores degradados cn un mundo degradado. Al describir a Encarna como "un ser de tierra" (201), Luis Martín Santos la exalta al rango de los arquetípos, ya que asi constata su condición de madre-tierra poseedora de indudables virtudes. Este es un hechodemostrado en su visita a la comisaría de la policía para rescatar a Pedro de la cárcel subterránea; al salvarlo, invierte los papeles de Orfeo y Eurídice y trastrueca el final convencional del mito órfico por otro igualmente cjemplar que es de índole positivas.

(3) Véasc, por cjcmplo, Juan Carlos Curutchct (1973: 36-37), y Betly Jcan (Jaige (1979: 101).

(4) Gustavo Pérez Firmat (1981: 199) constała la prescncia de cstc tópico en Thempo de silcncio.

(5) Véase cel artictulo de Ricardo Gullón (1972: 80-83) para un anátisis de tá función de los ntitos órficos en la novela de Martin Santos. 
Debido a su condición telárica, Encarna llega a ser la personificación de una fertilidad que se contrapone a la esterilidad de otras mujeres mencionadas $\mathrm{en}$ el libro. Tiene dos hijas, la primera de las cuales se llama 'Florita' porque ha brotado de la tierra-matriz (o carnal) de su madre; su nombre está arraigado tambićn en una larga tradición pictórica y literaria que, siglos ha, idealizó, en los versos de Lope de Vega y Pedro de Espinosa, a "la divina... mi hermosa Flor $a^{6}$. Hablando de flores y trasuntos literarios, tampoco deberíamos pasar por alto la semejanza entre la Encarna que da satisfacción sexual a su marido "sobre los campos de trigo en la vega del Tajo" (120), y Molly Bloom, la creación florida de James Joyce, quien hace el amor con Lcopoldo por primera vez "entre los rododendros del promontorio de Howth", allí donde el milcnario Liffey -el río de la vida- desemboca en el mar de Irlanda. Emblemas de la vitalidad y la fertilidad, ambos personajes se ajustan al molde arquetípico de la madre-naturaleza.

La referencia al río Tajo en la biografia de Encarna y sus hijas no carece de relevancia; al contrario, cxiste una estrecha relaciôn entre su origen geográfico y la fertilidad que simbolizan. El narrador hacc hincapié cn el hecho de que "las dos "a Toledo ortac' muchachas no rubias" se hayan gestado "en vientre toledano" (11) y destaca la fertilidad de "los retoños ya menstruanles de la familia" (29). En términos ginecológicos, establece así un fuerte contraste entre la abuela de Dorita quien lamenta "fa tragedia del derrumbe definitivo de mi vida de mujer" (22) -es decir, la menopausiay dos personajes que de olra forma quizá pareciesen ser de poca monta. Una imagen especialmente significativa en este respecto es la de Encarna vista momentos después de dar de comer a los ratones; según la detalladadescripción que da Martín Santos, Encarna "mantcría aún firmemente en su regazo cl pienso de los milagrosos ratones" (53). Suponiendo que el pienso esté compuesto de cereales, podríamos descubir en lá escena un preciosos singificado simbólico: Encarna, la ntadre-lierra fecundada por las aguas del río Tajo, cría en su vientrc toledano una rica cosecha, no solamente de flores sino también de cereales que son el sustento vital de unos animatillos "milagrosos".

Esta seric de lemas y símbolos no admite una explicación mecánica. Hay que reconocer que en la novela se mencionan toledanos que no ostentan los rasgos positivos a los cuales nos estamos reffriendo: cl nismo Muecas es nativo de un "Icjano pueblo toledano" (199), lo cual hace suponer que, según la tesis de Martín Santos, solamente la mujer toledana posee esas cualidades. Sin embargo, la existencia de uná "madre tolcclana" -la de Amador-que tiene una "seca matriz" (156) nos obliga a matizar nuestra lectura y a considerar otros factores aparte del tema del origen geográfico de los personajes. Un análisis de factores históricos y sociales podría ayudar a completar cl scntido último del libro.

En su printera visita a la chabola del Muccas, Pedro es recibido con "los gestos corteses heredados desde siglos antiguos por los campesinos de la campiña toledana" (49). Si es verdad que cn esta oración el narrador adopta un tono irónico, no

(6) Valgan de cjemplo cl famoso sonclo, "Estas purpúrcas rosas...", de Pedro de Ispinosa (1975: 18), y la no mcitos célebre descripción de Casilda en Pevibánez y el Comendador de Ocaña, de Iope de Vega (1979: 82).

(7) James Joyce (1969: 703). La traducción cs mía. 
se puede negar que atribuye a una clase campesina toledana ciertos valores espirituales y una herencia cultural que remonta hasta un pasado remoto. La relación histórica que esto implica se aclara al cotejar el pasaje con otro que narra la expericncia de Pcóro cuando vuclve borracho a su pensión en la noche del sábado. Nada más llegar, Pedro intenta despcjarse la cabeza con agua fría atraída a Madrid desde las provincias, y piensa en las diferencias que podría haber entre el Madrid actual y la antigua capital y próspero reino de Toledo. Reflexiona con especial detenimiento en la conquista de las tierras del rey Alcadir por los soldados de Alfonso VI, en "la Iejana noche de la edad media cuando cllos con su sable levantado consiguieron dar forma a expensas de la morisma de los campos de Toledo y de las zonas bajas donde [clla, la morisma] había empezado a trabajar las huertas, a la nucva nación" (99).

Las reflexiones de Pedro contienen una interpretación de la historia de España que considera las campañas alfonsinas de 1081 y 1085 como jalones decisivos cn la reconquista de la nación y su unificación bajo la monarquía católica. Sin cmbargo, Luis Martín Santos scruala que, al csforzarse por implantar csa unidad política, las fucrzas cristianas destruyeron un fructífero sistema de cultivos inaugurado por los moros cn las huertas de Toledo, c impusicron "el imperio de secano" (100) que sería asociado a partir de cse momento con la nucva capital, "la ciudad asćplica, sin huerta" de Madrid (99). La antitesis ferlilidad-csterilidad, que descmpeña un papel tan destacado cn el libro, cobra así un sentido más amplio, al identificarse la fertilidad como el signo de una antigua sociedad mixta - - da de judíos, moros y mozárabes $\mathrm{cn}$ el Toledo milcnario- çuc cxisticra antes de la formación del estado moderno que tendría su base institucional en Madrid.

De acuerdo con este esquema, Encarna-Ricarda y sus dos hijas toledanas se rclacionan con un principio histórico y social quc está profundamente arraigado $\mathrm{cn}$ la España pre-moderna. Esc principio se concibe de la mancra más justa, no como una esencia sino como una sustancia fértil y femenina que encama en la mujer del Muccas y'su descendencia. El nombre de 'Encarna', al que hace honores Matías en una sugestiva declaración en latín: "Inbilatio in came feminae" (72), demuestra ser sunamente importante para la comprensión de la novela. Sin cmbargo, si queremos dar cuenta cabal de la importancia de este personaje, convendría ofrecer una cxplicación del hecho de que tenga dos nombres, 'Encarna' y 'Ricarda'. Para más de un crítico, sc trata de un desliz cervantino perpetrado por cl aulor; ${ }^{8}$ en nuestra opinión, la doble nomenclatura cumple con una estricta función đentro de la estructura temática del libro. Los dos nombres, de ráy latina y germana respectivamente, designan los cstratos romanos y visigodos en la historia de Toledo, y, unidos $\mathrm{en}$ un solo personajc, Ilegan a representar un mestizaje que encama la verdadera sustancia histórica del pucblo cspañol. Estc complejo de factores históricos y sociales, en combinación con ci factor geográfico y cl scxual, define cl vator semántico de Encarna-Ricarda que cs una piezat-clave cn cl discño poćtico de Tiempo de silencio. ${ }^{9}$

(8) Véasc cl csłudio de Alronso Rey (1977: 29).

(9) Claude Talahite (1980: 30-40) dedica una sección de su inteligentc cstudio a una interpretación de Encarna-licarda. Nosotros compartimos muchos de tos puntos de vista cxpresados por csla colega francesa. 
Hechas estas observaciones, podemos dar un breve resumen y cvaloración de To expuesto en nuestro ensayo. Al estudiar la función de algunos de los personajes de Tiempo de silencio, hemos visto cómo Luis Martín Santos echa mano de una serie de imágenes arquetípicas del hombre y de la mujer para comunicar una visión amarga de la vida institucional de España. Mediante la descripción de tipos tales como la mujer-sircna y el hombre fálico, el autor pone en tela de juicio los lugares comunes sobre los que se asienta una idcología reaccionaria, y cumple así con su propósito de desmitificar los valores morales y políticos del régimen franquista ${ }^{10}$. De hecho, $\mathrm{cn}$ su exposición de los temas de la familia y la enfermedad, Martín Santos se apropia de unos tópicos retóricos para volverlos en contra del sistema que se vale de cllos para mantencrsc en cl poder. Al mismo ticmpo que realiza este trabajo desmitificador, $\mathrm{cl}$ autor hace uso -suponemos que consciente- del arquetipo de la madre-tierra y del mito órfico para destacar un elemento positivo, sustancial y redentor en el propio pueblo español. Gracias a esta cstrategia, asegura que su propia novela sca cl vchículo de un mensaje alentador y no la expresión de un nihilismo cstéril.

(10) La aulora del estudio más completo de Tiempo de silencio insiste $\mathrm{cn}$ el propósito desnitificador de Luis Manin Santos. Nos referimos a la hispanisia británica, Jo Labanyi (1985: 162-166) quicn, ch csic respecto, desarrolia una idca scminal de Juan Carlos Curutchet (1973: 40). 


\section{BIBLIOGRAFIA}

Craigc, Bctly Jcan. 1979, "Tiempo de silencio: le grand bouc and the Macstro". Revista de estudios hispánicos, XIII: 99-113. Alabama.

Curutchet, Juan Carlos. 1973, A partir de Luis Martin Santos Cuatro ensayos sobre la meva novela española, pp. 29-69. Montcvidco.

Espinosa, Pcdro de. 1975, Poesias completas. Ed. Francisco Lópcz Estrada. Madrid. Gullón, Ricardo. 1972, "Mitos órficosy cánccr social". El Urogallo, 17:80-89. Madrid. Joycc, Jamcs. 1967, A Portrait of the Arist as a Young Man. Harmondsworth.

1969, Ulysses. Harmondsworth.

Labanyi, .Jo. 1985, "Ironia c historia" en Tiempo de silencio. Madrid.

Pérez Firnat, Gustavo. 1981, "Repctition and Excess in Tiempo de silencio". PMLA, XCVI: 194-209. Nueva York.

Rey, Alfonso. 1977, Constncción y sentido de Tiempo de silencio. Madrid.

Talahite, Claude. 1980, "Ticmpo de silencio: unc ćcriture de silence". In Luis Martín Santos Tiempo de silencio, pp. 1.58. Montpeilier.

Vega, Lope de. 1979, Peribánez y el Comendador de Ocaña. Ed. Juan Maria Marín. Madrid. 